\title{
DEGRADAÇÃO E REVITALIZAÇÃO NO PROCESSO DE PLANEJAMENTO URBANO EM MARTINÓPOLIS / SP
}

\author{
Marcos Paulo da Silva', João Victor De Carvalho Brito ${ }^{1}$, Sibila Corral de Arêa Leão Honda² \\ ${ }^{1}$ Discente do curso de ARQUITETURA E URBANISMO da UNIVERSIDADE DO OESTE PAULISTA - UNOESTE. ${ }^{2}$ Docente do \\ curso de ARQUITETURA E URBANISMO da UNIVERSIDADE DO OESTE PAULISTA - UNOESTE.
}

\section{RESUMO}

O processo de planejamento urbano é ferramenta fundamental no processo de direcionamento e controle das cidades, visando a uma cidade mais justa e com ambientes adequados à vida em sociedade. Processos de degradação urbana deveriam ser identificados para que fossem restringidos por meio de ações públicas e privadas na tentativa de revitaliazação. Partindo desses fatos, esse artigo visa a iniciar discussão a respeito da degradação e da revitalização em cidades de pequeno porte, tendo como estudo de caso Martinópolis, no interior do Estado de São Paulo. Levantamentos de campo e aprofundamento teórico e conceitual embasam este trabalho. Verifica-se que tem ocorrido degradação urbana em cidades pequenas, reforçando a necessidade de direcionamento técnico, profissional e político.

Palavras-chave: Planejamento Urbano, Degradação do Espaço Urbano, Revitalização Urbana, Diversidade Urbana, Segregação Urbana.

\section{INTRODUÇÃo}

O planejamento urbano é muito importante para que as cidades cresçam ordenadamente, porém, foi somente a partir da Constituição de 1988 que a questão urbana passou a tomar forma legal definida. Até então, este tema estava envolto por controvérsias, especialmente quanto à competência dos municípios para agir em matérias urbanísticas e ambientais. A nova Constituição veio assegurar uma maior autonomia aos municípios, assim como maior liberdade para a gestão local.

Além dessa realidade, verifica-se a função do profissional Arquiteto e Urbanista e sua competência quanto à estruturação de planos e planejamento urbanos, seja no âmbito das diretrizes políticas gerais como nos planos setoriais. Aspectos de degradação intra-urbana, ou seja, de degradação de espaços urbanizados, são relevantes quanto ao planejamento e à gestão urbanos, e propostas de revitalização e requalificação são fundamentais no direcionamento das decisões políticas.

A partir disso, este trabalho está baseado nas discussões sobre a degradação urbana e diretrizes de revitalização no espaço urbano propostas na disciplina de Planejamento Urbano I do curso de Arquitetura e Urbanismo da Universidade do Oeste Paulista. 
Visa-se, então, neste artigo, a analisar questões de degradação da cidade de MartinópolisSP, município de pequeno porte no interior do Estado de São Paulo, verificando possíveis causas e definindo diretrizes de ação para sua revitalização.

Essa cidade se localiza na região oeste do estado de São Paulo, a $25 \mathrm{~km}$ de Presidente Prudente, sede regional, e $539 \mathrm{~km}$ da capital do Estado, possuindo 24.219 habitantes (CENSO 2010).

\section{METODOLOGIA}

A metodologia aplicada está baseada em aprofundamento teórico e levantamentos de campo, identificando os bairros e espaços urbanos, possibilitando compreender e associar a realidade às teorias da área de planejamento urbano, e estruturando diretrizes de intervenção, tendo como estudo de caso a cidade de Martinópolis, no Estado de São Paulo.

\section{ESTRUTURAÇÃO URBANA NA CIDADE DE MARTINÓPOLIS}

As ruas têm papéis importantes na imagem da cidade, visto que, se se parecerem interessantes, a cidade resultará interessante, e, ao contrário, se se parecerem monótonas, a cidade será identificada como monótona (JACOBS, 2000).

E, os principais espaços públicos para o usuário individual são as calçadas, cuja função, além de acolher os pedestres, é a manutenção da segurança urbana. Precisa ser movimentada de noite e de dia por diferentes populações. Enquanto isso, os vizinhos mantêm os olhos sobre as ruas verificando se está acontecendo algo de errado; o que Jacobs (2000) denomina de "sistema de vigilância cidadã", existindo, no entanto, quando há uma boa diversidade de usos nos edifícios ao redor.

Considerando a cidade de Martinópolis, na região central se percebe grande trânsito de pessoas em horários diversificados para as mais diferentes atividades, já que é o lugar onde mais se percebe a diversidade, contendo a maior concentração de comércios e serviços, porém poucas residências.

Em outros bairros, o movimento de pessoas passando pelas ruas diminui consideravelmente, deixando os bairros mais monótonos. No entanto, em alguns lugares desses bairros nota-se que alguns moradores se reúnem em suas calçadas para conversar, possibilitando crianças brincando nas ruas, resultando em grande vitalidade e segurança. 
E, na região onde se localizam os bairros Parque das Grevilhas, Arthur Galvão, João Cordeiro, Pedro e Zulmira Bergamini, e Jardim Scatolon, o trânsito de pessoas é semelhante ao da região central, porém em escala pouco menor. Isso ocorre porque como essa região é a mais afastada do centro, é necessário que haja uma demanda de comércios e serviços suficientes para atender a população que reside na área, gerando uma certa diversidade, que faz com que as pessoas caminhem de suas casas aos pontos de seus interesses. Por ser uma região onde a movimento de carro é menor, percebe-se a liberdade que as crianças têm para brincar nas ruas e calçadas e os moradores de se reunirem com seus vizinhos, tornando um ambiente bastante familiar e seguro.

Assim como as ruas, os parques são elementos que podem contribuir para a vitalidade urbana, pois possibilitam grande fluxo de pessoas e diversidade de atividades, mas as pessoas precisam querer estar neles, atribuindo-Ihe utilidade. Segundo Jacobs (2000, p.98):

Se perguntarmos a um construtor como fazer para melhorar seu projeto na cidade tradicional, ele responderá, como se fosse uma virtude patente: Mais Áreas Livres. Se perguntarmos a um técnico sobre os avanços nos códigos de zoneamento progressistas, ele mencionará, mais uma vez como uma virtude patente, os incentivos a Mais Áreas Livres. Se andarmos com um planejador por um bairro desvitalizado, já marcado por parques vazios e jardins descuidados cheios de papeis velhos, ele vislumbrará um futuro de Mais Áreas Livres.

Mas, para entender como é a influência dos parques na cidade, é preciso acabar com a confusão entre os seus usos reais e os fantasiosos. Jacobs (2000) afirma que são necessários cerca de 12 mil metros quadrados de árvores para absorver a quantidade de dióxido de carbono que quatro pessoas liberam ao respirar, cozinhar e aquecer a casa. Na verdade, são as correntes de ar e não os parques que evitam que a cidade sufoque (JACOBS, 2000).

E a grande questão é por que é tão frequente se ver parques vazios? Por que não existem parques onde há gente? Os parques vazios não implicam apenas em dinheiro mal gasto e oportunidades perdidas. Além disso, eles podem ter efeitos negativos nos bairros e nas cidades. Sofrem do mesmo problema das ruas cegas. Suas ameaças se espalham pela vizinhança, fazendo com que as pessoas evitem também as ruas que ficam próximas a estes parques. Jacobs (2000) defende que os parques urbanos são diretamente afetados pela maneira como a vizinhança interfere neles.

Em Martinópolis, no centro da cidade, percebe-se o bom uso das praças, com movimento de diferentes pessoas em diferentes horários do dia, inclusive no período noturno, devido aos 
costumes da população de se reunir para conversar nas praças. Assim também ocorre nos demais bairros, onde a maioria das praças são utilizadas pelos moradores.

Essas questões possibilitam e estimulam a diversidade urbana nessa cidade. Pois, segundo Jacobs (2000, p.246):

A diversidade urbana emerge, do tipo que é catalisada pela associação de usos principais combinados, ruas frequentes, mistura de prédios de várias épocas e custos e forte concentração de usuários, não acarreta as desvantagens da diversidade comumente presumida pela pseudociência do urbanismo. [...]

Em contraposição à diversidade e à vitalidade urbanas, a segregação diferencia e afasta áreas e população da cidade. Villaça (2001, p.142) define a segregação como "um processo segundo o qual diferentes classes ou camadas sociais tendem a se concentrar cada vez mais diferentes regiões gerais ou conjunto de bairros" e Lojkine (1981 apud VILLAÇA, 2001, p.147) subdivide a segregação em:

1) uma oposição entre o centro, onde o preço do solo é mais alto, e a periferia; 2) uma separação crescente entre as zonas e moradias reservadas às camadas sociais mais privilegiadas e as zonas de moradia popular; 3) um esfacelamento generalizado das funções urbanas disseminadas em zonas de escritórios, zona industrial, zona de moradia, etc. $[\ldots]$

Em Martinópolis, percebe-se que existe clara segregação segundo a dicotomia centro versus periferia, onde no centro tem alta concentração de estabelecimentos comerciais e de serviços, com lotes mais caros e ocupados pelas classes de rendas mais altas, e nos bairros mais afastados se vê apenas residências mais simples ou conjuntos habitacionais.

Considerando outro conceito de segregação em "segregação voluntária", quando pessoas de mesma classe tendem a viver próximas, por sua própria vontade, e "segregação involuntária", quando as pessoas se sentem obrigadas a morar ou deixar de morar em determinadas áreas, devido as mais variadas forças. (GIST e FAVA, 1968, p.160 apud VILLAÇA, 2001, p.147).

Partindo da afirmação acima, percebe-se que em Martinópolis, no bairro Jardim Pioneiro, ocorre a segregação voluntária, pois é a escolha clara de moradores das classes mais altas, passando a ser sinônimo de status. Essa segregação fica mais evidente pelo fato de o bairro ser limitado em um de seus lados pela barreira da linha férrea, evidenciando o contraste entre os dois lados, já que no outro lado localiza-se a área invadida do bairro Jardim Bela Vista. 
Ou seja, outro aspecto que contribui para a segregação em Martinópolis é o fato d a linha férrea cortar a cidade, formando uma barreira urbana, segregando o "lado de lá" (VILLAÇA, 2001). Importante destacar que há apenas três pontos de transposição a essa barreira urbana, com passagens em nível. Este fato é agravado pela existência de vazios urbanos e outros elementos que formam outras barreiras urbanas, como o cemitério.

\section{DEGRADAÇAO E REVITALIZAÇAO EM MARTINÓPOLIS}

Em Martinópolis, até pouco tempo, não havia discussões claras referentes ao planejamento da cidade. O tecido urbano foi formado simplesmente pelos proprietários que loteavam suas terras. Em relação às áreas de lazer, sua definição tem sido apoiada diretamente nas exigências legais, mas são bem aceitas e utilizadas pela população, dando mais vida ao bairro.

Nessa cidade, no entanto, percebe-se que alguns pontos são marcados pela degradação, por motivos diversos. A segregação produziu algumas áreas degradadas, uma delas é a área do "Buracão", região do bairro Vila Alegrete, que tem esse apelido devido ao fato de que há alguns anos existia uma voçoroca. Nessa área a população de baixa renda se concentrou e, devido a vários motivos, e entre a construção de uma penitenciária nas proximidades, se tornou uma região com alta taxa de criminalidade, além de divulgado ponto de tráfico de drogas.

Isso acaba expulsando parte os moradores para outras regiões, gerando um aspecto de abandono, além do fato da Prefeitura Municipal não definir políticas de recuperação da área e não destinar recursos a essa região. Atualmente a área foi considerada área de risco, e a Prefeitura elaborou um plano para remoção dos moradores das áreas mais perigosas, por meio da criação de habitações de interesse social em outra área, mas não obteve o sucesso desejado, já que alguns moradores invadiram a área novamente.

Outros três casos são as áreas formadas por invasões de áreas que seriam destinadas a construção de praças nos bairros Oasis Parque Residencial e Jardim Bela Vista, e de uma área onde funcionava um aterro sanitário municipal no Jardim Alegrete. Os moradores invadiram e construíram suas residências de forma simples.

Existem, entretanto, alguns poucos casos recentes voltados ao planejamento e à gestão urbanos nessa cidade, incluindo propostas de revitalização urbana, como o problema da barreira da linha férrea, que, além da abertura de novas passagens em nível para travessia da linha, foram demolidas algumas edificações existentes para a construção de uma praça, que trouxe presença 
de pessoas em vários períodos do dia em um local que antes era utilizado somente como passagem.

Em relação a processos de revitalização urbana Jacobs (2000, p.438) explica:

[...] os projetos que precisam ser revitalizados com mais urgência são os conjuntos habitacionais de baixa renda. Seus insucessos têm efeitos drásticos sobre a vida de muitas pessoas, principalmente crianças. Além do mais, por serem por si só muito perigosos, degradantes e instáveis, em vários casos é muito difícil manter um nível de civilidade tolerável nas redondezas.

Assim, verifica-se a forte necessidade de ação política nas áreas degradadas de uso e residência de população carente, como a Vila Alegrete, próxima ao "Buracão". Deve-se pensar em um aumento da diversidade de usos, com a inserção de diferentes estabelecimentos comerciais, além de institucionais e de serviços, que supram as necessidades dos moradores.

Jacobs (2000) afirma que ao buscar projetos de revitalização, deve-se pensar na área como parte de um conjunto, reintegrando essa região ao conjunto urbano, fortalecendo não só essa área, como também a cidade como um todo.

Sendo assim, diretrizes de planejamento deve focar na criação de áreas de lazer que possam ser usadas tanto pelos moradores da área, como pelos moradores dos bairros em seu entorno.

\section{CONSIDERAÇOES FINAIS}

Para a revitalização de áreas urbanas, as intervenções arquitetônicas, sozinhas, não são suficientes, devendo ser complementadas por outras intervenções do poder público. Profissionais de formação específica, ou seja, profissionais com atribuição para estudos e redirecionamento intra-urbano são fundamentais.

A preocupação com os processos urbanos precisam ocorrer, com discussões e propostas de revitalização, visto que a degradação de ambientes urbanos geram graves problemas à toda sociedade. E essa realidade também deve incluir cidades de pequeno porte, pois também têm sido atingidas pelos rápidos ciclos de degradação física e abandono político e social.

\section{REFERÊNCIAS}

INSTITUTO BRASILEIRO DE GEOGRAFIA E ESTATÍSTICA - IBGE. Censo 2010. Disponível em: http://www.ibge.gov.br/cidadesat/painel/painel.php?codmun=352920. Acesso em 03 jun 2013.

JACOBS, Jane. Morte e Vida de Grandes Cidades. São Paulo:Martins Fontes, 2000. 
Encontro de Ensino, Pesquisa e Extensão, Presidente Prudente, 21 a 24 de outubro, 2013

VILLAÇA, Flávio. Espaço Intra-Urbano no Brasil. São Paulo: Studio Nobel, 2001. 